\title{
Relações apositivas: dinâmica dos lugares de enunciação nas relações de designação
}

\author{
Eduardo Guimarães ${ }^{1}$ \\ Universidade Estadual de Campinas
}

O objetivo geral deste texto é discutir alguns aspectos da constituição da designação no acontecimento de enunciação. Tal como temos feito, tratamos a designação a partir da posição que considera a relação com as coisas como produzida pela significação da linguagem: a produção da designação se dá pelo modo como se constitui a alocução no acontecimento de enunciação. A alocução é uma relação, dizendo de modo genérico, entre aquele que diz e aquele para quem se diz. As relações da alocução têm sido consideradas na semântica da enunciação, tal como tenho feito, no que chamo de cena enunciativa, que se organiza pelo agenciamento do falante, de um lado, em Locutor (o lugar daquele que diz) e, de outro, em alocutor (o lugar social do dizer), ambos com seus correlatos correspondentes: Locutário e alocutário. De outra parte, o acontecimento de enunciação estabelece, pela divisão dos lugares própria do agenciamento, uma outra relação: entre o enunciador (lugar de dizer) e aquilo sobre o que se diz. Neste quadro meu interesse é pensar esta relação com o que se diz, que constitui as designações, na sua relação com a alocução e assim refletir sobre como a produção da significação constitui a designação e assim torna possível a referência. Para isso vou procurar olhar para uma relação no interior dos enunciados que é capaz de nos colocar claramente diante do funcionamento da designação. Ao olhar para a própria construção linguística somos levados a olhar para a constituição de sua relação com aquilo de que fala.

Para isso meu objetivo mais específico é refletir sobre as questões da produção da designação observando uma relação muito particular entre as expressões linguísticas, a chamada relação apositiva. Vou, portanto, partir diretamente de uma relação de linguagem que se mostrará, por outra parte, como produtora da relação da linguagem com aquilo de que fala, em virtude mesmo de significá-la. Tal como já coloquei em textos anteriores (Guimarães, 2011, 2012, 2014) a relação apositiva pode ser caracterizada como um procedimento de reescrituração e não de articulação.

Tratar a relação dita apositiva como reescrituração coloca em pauta construções que devem ser tratadas como relações de reescrituração e não de articulação de enunciados ou de elementos de enunciados ${ }^{2}$. Por outro lado isto leva a análise desta relação para fora de qualquer consideração do aposto como uma relação do tipo do adjunto adnominal (na terminologia gramatical tradicional). Tendo em vista nosso objetivo, que não é descrever a relação apositiva, mas refletir sobre a designação e a dinâmica da cena enunciativa a partir do estudo do aposto, vou fazer três sondagens diferentes. Inicialmente, vou fazer uma sondagem a partir de um recorte de um texto específico e tomar um enunciado em que encontramos, no mesmo enunciado, mais de uma relação apositiva. Em seguida tomaremos alguns textos em torno de enunciados com a relação apositiva envolvendo um nome próprio. Numa terceira sondagem,

\footnotetext{
${ }^{1}$ Doutor em Linguística pela USP. Docente do Instituto de Estudos da Linguagem da UNICAMP, membro do LABEURB e pesquisador do CNPq. eduardo.gui@uol.com.br

${ }^{2}$ Sobre a distinção reescrituração e articulação ver, por exemplo, Guimarães $(2002,2007)$
} 
voltaremos sobre os enunciados considerados para observar especificamente como se apresenta a divisão dos lugares de enunciação e os modos de integração dos elementos da relação apositiva ao texto.

\section{Relações Apositivas}

Para a primeira sondagem observemos o funcionamento do chamado aposto pela análise do recorte (1) abaixo, do texto "A Linguagem em Desmundo e Como Era Gostoso o meu Francês" 3 .

(1) O primeiro é baseado no diário do viajante alemão Staden(a), feito prisioneiro pelos índios tupinambás(b) - adeptos do canibalismo(c) - no Brasil do século XVI.

Este recorte está no segundo parágrafo do texto e o primeiro é uma reescrituração do nome do filme Como era gostoso o meu francês. Neste recorte temos várias relações que são consideradas apositivas ${ }^{4}$ : (a) o viajante alemão Staden (em itálico o termo considerado aposto); (b) Staden, feito prisioneiro pelos índios tupinambás; e (c) os índios tupinambás - adeptos do canibalismo. Para o que interessa aqui, vou me valer inicialmente da formação apositiva (c). O chamado aposto adeptos do canibalismo reescritura por expansão os índios tupinambás. Por esta reescrituração, pode-se dizer que este aposto atribui sentido a os índios Tupinambás. Ou seja, a os índios Tupinambás está atribuído o sentido de adeptos do canibalismo (adeptos do canibalismo desenvolve o sentido de os índios tupinambás). Só para registrar outra possibilidade de reescrituração apositiva, no caso de (a), por exemplo, há uma reescrituração por substituição sinonímica de o viajante alemão por Staden. Em outras palavras, para este modo de abordar esta relação, o funcionamento das expressões apositivas (tanto no caso de (c) que vamos observar um pouco mais aqui, como no caso de (a)) se caracteriza por uma relação de reescrituração. Além deste aspecto fundamental, é preciso observar outros, envolvidos no caso.

Consideramos para (1) as seguintes paráfrases:

(1.a) O primeiro é baseado no diário do viajante alemão Staden, feito prisioneiro pelos índios tupinambás no Brasil do século XVI.

(1.b) Os tupinambás são/eram adeptos do canibalismo.

Relativamente a este parafraseamento, podemos considerar que se tomarmos o enunciado negativo (1.c) abaixo, vemos que a negação em nada afeta o sentido de (1.b):

(1.c) O primeiro não é baseado no diário do viajante alemão Staden(a), feito prisioneiro pelos índios tupinambás(b) - adeptos do canibalismo(c) - no Brasil do século XVI.

Neste caso (1.c) seria parafraseável por

\footnotetext{
3 “A Linguagem em Desmundo e Como Era Gostoso o meu Francês", Ciência e Cultura, ano 57, no. 2, SBPC, junho de 2005 , p. 51.

${ }^{4}$ Retomo aqui elementos de textos como Guimarães $(2011,2012,2014)$. Em outro momento incluí nestas relações $O$ viajante alemão, considerando alemão como aposto. Mas julgo que efetivamente, neste caso, o melhor é considerar alemão como articulado à expressão nominal o viajante.
} 
(1.a') O primeiro não é baseado no diário do viajante alemão Staden, feito prisioneiro pelos índios tupinambás no Brasil do século XVI.

e

(1.b) Os tupinambás são/eram adeptos do canibalismo.

A negação em (1.c) não afeta (1.b). Isto quer dizer que a reescrituração apositiva se apresenta enunciativamente de modo distinto do elemento reescriturado.

Por outro lado, se tomamos o modo de marcar por travessões a inserção do aposto em (c) no enunciado do recorte (1), vemos que ela não se deu por algo como,

(1.b') que eram adeptos do canibalismo.

Há um deslize (são/eram) do narrado para o presente da enunciação do texto (a característica da antropofagia está no texto em análise significada no presente permanente, mesmo que isto não seja mais verdade).

Estes dois aspectos nos levam a considerar uma divisão desta enunciação em dois enunciadores; podemos considerar também que o lugar social do dizer é o de jornalista (alocutor-jornalista - al-jor), já que o texto é uma "notícia" em uma revista de divulgação científica (nesta medida consideramos nesta alocução um alocutário-leitor at-leitor). A cena poderia ser representada como segue.

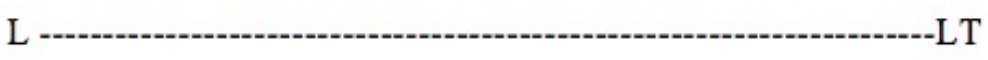

E-1 - Os tupinambás são/eram adeptos do canibalismo (1b)

E-2 - O primeiro é baseado no diário do viajante alemão

Staden, feito prisioneiro pelos índios tupinambás no Brasil

do século XVI (1.a)

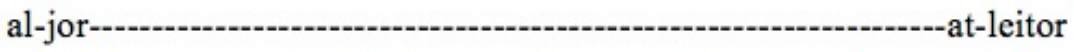

Levando em conta esta divisão dos enunciadores, podemos considerar ainda que (1.b) pode também, em certa medida, ser parafraseado por e (1.a) por

(1.b’') Os tupinambás, todos sabemos, são/eram adeptos do canibalismo.

(1.a') Eu digo que o primeiro é baseado no diário do viajante alemão Staden, feito prisioneiro pelos índios tupinambás no Brasil do século XVI.

Isto leva a considerar que E-1 é, neste caso, um enunciador genérico (Egco). Ou seja, o que se diz em (1.b) se apresenta como algo difuso, mas do conhecimento de todos. Por outro lado, E-2 é um lugar de dizer individual. Ao mesmo tempo podemos observar que o alocutor-jornalista fica significado como apresentando-se como responsável pelo dito em (1.a). Há, portanto, aqui uma relação entre al-jor e E-2, como própria de uma dinâmica interna da cena que significa este aposto. Podemos considerar que o alocutor-jornalista apresenta o enunciador individual (representamos esta relação de apresentação do E-2 pelo alocutor-jornalista por uma seta de maior espessura, tal 
como se verá no esquema abaixo). Esta apresentação é que significa, de certo modo, que o alocutor "diz como seu" o dizer do enunciador individual.

Esta análise ${ }^{5}$ nos leva a caracterizar a reescrituração apositiva como apresentando sempre um desdobramento de enunciadores. No conjunto pode-se dizer que o alocutor apresenta um enunciador-individual que enuncia o elemento determinado semanticamente (os indios tupinambás) da reescrituração apositiva, enquanto o outro lugar de dizer (o enunciador genérico) traz a reescrituração apositiva, adeptos do canibalismo, que determina semanticamente o elemento reescriturado que está em (1.a), os índios tupinambás. Ou seja, os elementos da relação apositiva se apresentam por lugares de dizer diferentes. Estes lugares de dizer diferentes se relacionam, não só por conviverem na mesma cena, mas especificamente porque o E-1 (genérico) diz em relação ao dito pelo E-2 (individual). Ou melhor, o E-2 diz como se reportando ao dizer de E-1. Trata-se, segundo minha análise da dinâmica da cena, de uma alusão que E-2 faz a E-1.

A se ressaltar aqui que a reescrituração apositiva se dá numa relação de contiguidade que não se caracteriza como uma relação de articulação. E o que faz esta distinção é que um elemento é dito de lugares de dizer diferentes de tal modo que o enunciador do elemento reescriturado alude o enunciador do elemento aposto (o que no esquema abaixo e é representado por uma seta de menor espessura $)^{6}$.

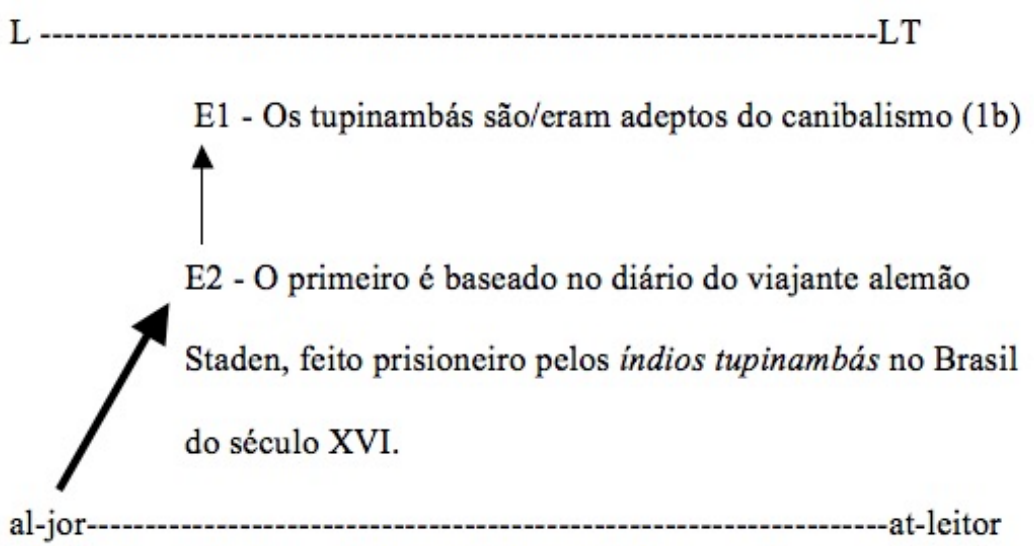

Observando a relação de atribuição de sentido produzida pela reescrituração, observa-se que o que é dito do lugar de E-2 como os índios tupinambás é determinado semanticamente pelo que é dito do lugar de E-1, adeptos do canibalismo. Se o aposto atribui sentido à formação nominal de que é aposto, isto não se apresenta como ação de um lugar único, mas como produzido pela divisão dos lugares de enunciação na cena enunciativa.

\section{Relações Apositivas: Reescrituração de Nomes}

Passemos agora à segunda sondagem, que será feita pela análise das expressões com relação apositiva nos enunciados dos três textos abaixo, o que colocará em pauta outros aspectos.

\footnotetext{
${ }^{5}$ Ela pode ser replicada, tal como mostrei em Guimarães (2012), para os outros funcionamentos apositivos do recorte (1).

${ }^{6}$ Este modo de tratar o funcionamento da dinâmica da cena e da relação entre seus lugares, coloca no centro da solução a consideração de que tudo se organiza em virtude de que todo dizer, acontecimento, é dizer de outro dizer.
} 


\section{Texto 1}

\section{Dunga xinga jornalista Alex Escobar da Globo}

Enviado em 21 de jun de 2010

Os ânimos exaltados e a violência do segundo tempo do jogo contra a Costa do Marfim contaminaram o técnico Dunga. Após a expulsão de Kaká, ele chamou o juiz de "ladrão". Depois, nos instantes finais da partida, xingou o atacante Drogba. Em português mesmo, sem intenção de ser compreendido pelo jogador.

$\mathrm{Na}$ entrevista coletiva após a partida, o sangue do treinador ainda estava quente. Quando acusava os jornalistas de ter cobrado a saída de Luis Fabiano do time titular, Dunga viu Alex Escobar, jornalista da TV Globo, que conversava ao telefone com um colega, balançar a cabeça. Nesse momento, o técnico da seleção brasileira interrompeu a frase para interpelar Escobar.

(...)

(https://www.youtube.com/watch? $\mathrm{v}=\mathrm{mm}$ yn4-1QN4 - (acessado em 12 de maio de 2017).

\section{Texto 2}

\section{Dunga Xinga Alex Escobar, Jornalista da Globo!}

$\mathrm{Na}$ entrevista coletiva após a partida, o sangue do treinador ainda estava quente. Quando acusava os jornalistas de ter cobrado a saída de Luis Fabiano do time titular, Dunga viu Alex Escobar, jornalista da $T V$ Globo, que conversava ao telefone com um colega, balançar a cabeça.

Nesse momento, o técnico da seleção brasileira interrompeu a frase para interpelar Escobar. Em seguida, ficou balbuciando palavrões que vazaram no sistema de som da sala de entrevistas. Xingamentos gratuitos que foram ouvidos por toda a imprensa internacional presente.

(...)

(https://tvibopenews.wordpress.com/2010/06/20/dunga-xinga-alex-escobarjornalista-da-globo/ - (acessado no dia 12 de maio de 2017).

\section{Texto 3}

Dunga xinga árbitro e jornalista após vitória contra a Costa do Marfim

Sistema de som da sala de imprensa reproduz xingamentos do treinador a um jornalista da Rede Globo

Luiz Antônio Prósperi, do Jornal da Tarde

20 Junho $2010 \mid 22 \mathrm{~h} 51$

JOHANNESBURGO - Dunga saiu do campo chutando a grama e gritando contra o árbitro francês Stephane Lannoy. Não engoliu a expulsão de http://topicos.estadao.com.br/kaka Kaká nem os pontapés que seus jogadores levaram dos africanos da Costa do Marfim.Desde os primeiros instantes do jogo, ele não conseguiu disfarçar sua irritação com o juiz. Xingou até a quarta geração de Lannoy.

(...)

(http://esportes.estadao.com.br/noticias/futebol,dunga-xinga-arbitro-e-jornalistaapos-vitoria-contra-a-costa-do-marfim,569537 - (acessado em 12 de maio de 2017).

Comparando os três textos, um primeiro aspecto a levar em conta é que

(2.1) Dunga xinga jornalista Alex Escobar da Globo

e 
(2.2) Dunga xinga Alex Escobar, Jornalista da Globo!

são títulos do texto 1 e do texto 2. Em vista disso temos que considerar que cada um dos textos reescritura por expansão seu título. Por outro lado os dois textos integram um enunciado tal como

(2.3) Dunga viu Alex Escobar, jornalista da TV Globo, que conversava ao telefone com um colega, balançar a cabeça.

que traz um aposto nas mesmas condições do aposto de (2.2).

No texto 1 encontramos o enunciado (2.1) como título e encontramos igualmente um enunciado como (2.3).

No texto 3 há o seguinte título:

(2.4) Dunga xinga árbitro e jornalista após vitória contra a Costa do Marfim

que não traz a relação que estamos observando, mas indica uma característica interessante presente nos enunciados (2.1) e (2.3), títulos de textos. Nestes enunciados título o nome comum jornalista não aparece com o determinante $o$. Não há neles $o$ jornalista, mas jornalista, característica que se repete em (2.3) que não é título de nenhum dos textos considerado nesta sondagem.

Por outro lado em (1), da primeira sondagem, temos a relação de aposto na expressão $o$ viajante alemão Staden, em que o nome comum, que terá como aposto o nome próprio, aparece com o determinante. $\mathrm{O}$ mesmo ocorre com o enunciado

\section{(2.5) Porque Dunga xingou o jornalista Alex Escobar}

Ou seja, não se pode dizer que é próprio do aposto incidir sobre uma formação nominal com nomes comuns sem o determinante (esta formação nominal pode ter ou não o determinante), pois, como apresentado acima, encontramos um nome comum com ou sem determinante sendo reescriturado pelo aposto.

Isso leva a perguntar que expressões estão envolvidas na relação apositiva, se consideramos o viajante alemão Staden de (1), e o jornaista Alex Escobar em (2.5). Observemos estes aspectos a partir de o viajante alemão Staden, pensando nos enunciados (2.1) (2.2) e (2.3), nos quais o determinante não aparece. Poderíamos pensar que se tem algo como:

[O [Viajante alemão //Staden ]].

Ou seja, teríamos algo como Staden é aposto de viajante alemão e teríamos, pela hipótese que adotamos, que Staden reescritura viajante alemão e viajante alemão reescritura, por simetria, Staden.

Isto se daria também para o caso de (2.5), por exemplo:

[O [jornalista // Alex Escobar] $]$

Alex Escobar seria aposto de jornalista, o que nos leva a dizer que Alex Escobar reescritura jornalista, e vice-versa. 
Isto seria correspondente a considerar que, em (2.1), Alex Escobar é aposto de Jornalista da Globo. O que leva a considerar que jornalista da Globo é reescriturado por Alex Escobar (e vice-versa).

Mas esta solução não parece ser razoável, porque deste modo teríamos que considerar como um elemento [o viajante alemão Staden ] e dentro dele haveria uma relação de aposição entre viajante alemão e Staden. Tanto viajante alemão quanto Staden seriam elementos da formação nominal o viajante alemão Staden (o mesmo se daria para (2.5)). Isto corresponderia a negar o caráter de reescrituração envolvido na relação apositiva. Em virtude disso temos que considerar para este caso que Staden é aposto de o viajante alemão e que Staden reescritura o viajante alemão, assim como o inverso. Isto significa que o que há é uma relação como

[O Viajante alemão] [Staden ],

em que Staden não é um elemento da formação nominal o viajante alemão Staden. Staden é uma outra formação nominal que reescritura o viajante alemão. O mesmo se dando para

[o jornalista da Globo] [Alex Escobar].

O decisivo na relação apositiva é que se trata de uma relação de natureza claramente nominal, que não é nem coordenação nem subordinação (dependência), que não é uma relação de articulação.

\section{Relação Apositiva: Modos de Integração ao Texto}

Passemos à terceira sondagem. Retomemos

(2.3) Dunga viu Alex Escobar, jornalista da TV Globo, que conversava ao telefone com um colega, balançar a cabeça.

Podemos considerar, tal como fizemos para o enunciado (1), na primeira sondagem, a negação do enunciado (2.3):

(2.3a) Dunga não viu Alex Escobar, jornalista da $T V$ Globo, que conversava ao telefone com um colega, balançar a cabeça.

Também aqui encontramos uma diferença no modo de apresentação do que se diz no aposto e no termo ao qual o aposto se relaciona.

Podemos considerar que o aposto jornalista da TV Globo se apresenta de um modo diferente de Dunga não viu Alex Escobar balançar a cabeça. Isto porque a negação não afeta o aposto. Este aspecto se confirma se consideramos a continuidade do texto. Nele o que da relativa retoma Alex Escobar, o termo reescriturado pelo aposto. Ou seja, o encadeamento é Alex Escobar que conversava... Teríamos algo como

(2.3b) Dunga viu Alex Escobar, que conversava ao telefone com um colega, balançar a cabeça.

Ou seja, o modo de o aposto (jornalista da TV Globo) integrar-se ao texto é diferente do modo de se integrar ao texto de Dunga viu Alex Escobar balançar a 
cabeça. E mais especificamente podemos dizer que, no enunciado (2.3), Alex Escobar é um termo que se integra ao enunciado Dunga viu Alex Escobar, jornalista da TV Globo, balançar a cabeça diferentemente de jornalista da TV Globo. Alex Escobar é o centro de uma formação nominal da qual jornalista da TV Globo é um aposto, exatamente por não estar articulado a Alex Escobar nem por coordenação, nem por subordinação, nem por incidência.

Tomemos aqui um outro texto.

\section{Texto 4}

Porque Dunga xingou o jornalista Alex Escobar

Por@23/06/2010 às 02:13

Diálogo entre jornalista Marco Aurélio Melo, editor especial do Jornal da Record e o técnico da seleção brasileira Dunga. O diálogo foi publicado na manhã de 22 de junho, no blog do jornalista

- Alô.

- Como vai comandante?

- Bem, e você, meu caro?

- Muito bem também. O país parou ontem para discutir sua reação, depois do jogo de domingo.

-Eu sei, eu sei... Tenho visto as informações.

- Mas, afinal, o que aconteceu?

- Eu estava respondendo à pergunta quando o jornalista começou a me criticar pelo telefone, na minha frente. Perguntei se era comigo e ele amarelou. Foi um cagão. E não é a primeira vez.

- A empresa em que ele trabalha te criticou abertamente durante o programa de maior audiência anteontem à noite.

- Eles vão me criticar enquanto durar a Copa do Mundo. E sabe por quê? Porque eles perderam a exclusividade de falar com quem queriam, a hora que queriam, de pressionar, de escalar jogador. Acabou a bagunça! Acabou a zona mista (área reservada da concentração onde jogadores, jornalistas, patrocinadores, convidados ficavam juntos). Fechei o treino...Tudo isso deixou eles muito irritados. Só que eles não podem falar abertamente, então eles usam seus "vassalos", como você costuma chamar a matilha de pit bulls aí no DoLaDoDeLá. No caso desse jornalista, por que ninguém pergunta o que ele fazia no início da carreira? Por que ninguém conta que tem gente que se aproveita do talento de profissionais sérios para subir na profissão?

(....)

(https://midiaindependente.org/pt/red/2010/06/473706.shtml - (acessado em 20 de maio de 2017).

Tomemos deste texto o seu título, que é o enunciado:

(2.5)Porque Dunga xingou o jornalista Alex Escobar.

Levando em conta a possibilidade de

(2.5a)Porque Dunga não xingou o jornalista

podemos considerar para (2.5) as seguintes paráfrases

(2.5b)Porque Dunga xingou o jornalista

(2.5c)(eu digo que) o jornalista (de que falo) é Alex Escobar 


\section{(2.5d)(eu digo que) Alex Escobar é jornalista}

Se consideramos agora a questão da continuidade do texto, a partir deste enunciado, vamos observar que o texto, todo o diálogo, se apresenta como um desenvolvimento de (2.5), e o que está em (2.5c) e (2.5d) são elementos de sentido que são dados por um lugar diferente do lugar de dizer que enuncia (2.5b), assim como dá continuidade a (2.5b). Ou seja, o modo de integração de (2.5b), de um lado, e (2.5c) e (2.5d) ao texto é diferente. E não parece razoável dizer que se trata de uma relação de pressuposição ${ }^{7}$. No caso de $(2.5 \mathrm{~d})$, por exemplo, trata-se de uma predicação. E isto combina facilmente com a consideração do aposto como reescrituração.

Vemos então que há um aspecto geral no funcionamento do aposto que se enuncia a partir de uma divisão dos lugares de dizer. Assim a consideração destes aspectos retira a reflexão do lugar que tenta resolver uma certa questão veritativamente, tomando-a como uma diferença no modo de integração ao texto. Aqui podemos, seguindo o que já fizemos na primeira sondagem, facilmente considerar:

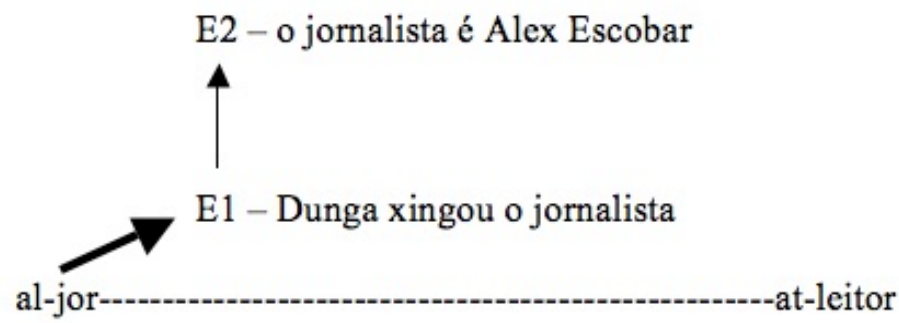

Ou seja, o q4-jor apresenta E-1 que alude a E-2. A alocução do alocutor ao alocutário traz ainda uma relação de alusão entre dois lugares de dizer. Este funcionamento leva a observar que isto pode mostrar a diferença entre o aposto $\mathrm{NPr} / \mathrm{N}$ e N/NPr. Lembramos aqui que para a atribuição de sentido no primeiro caso (como em 2.2) há algo como um predicado ser $N$ e no segundo caso (como em 2.5), um predicado como é o mesmo que N. No primeiro caso teríamos Alex Escobar é jornalista da Globo e no segundo teríamos o jornalista é o mesmo que Alex Escobar. No entanto isto continua a significar Escobar é jornalista, em virtude da constituição da designação do NPr Alex Escobar, como algo que também se significa na relação apositiva, em virtude da simetria da reescrituração. Em 2.5, a expressão referencial o jornalista faz a mesma referência que Alex Escobar. Isto se deve a que a expressão referencial o jornalista traz a designação de jornalista com a qual se refere a alguém que é referido também por um nome próprio Alex Escobar. Nesta medida jornalista atribui sentido a Alex Escobar neste enunciado.Tem-se assim neste caso a determinação (atribuição de sentido) de Alex Escobar sobre o jornalista, na medida mesma em que Alex Escobar especifica o jornalista. Só é possível referir a algo por o jornalista ou o viajante se a designação de jornalista ou de viajante estiverem presentes. Então se o jornalista † Alex Escobar isto só se dá porque jornalista †Alex Escobar (Alex Escobar é jornalista), o mesmo se dá para o viajante $\dashv$ Staden porque, na mesma medida, viajante $\dashv$ Staden (Staden é viajante).

\footnotetext{
${ }^{7}$ A pressuposição de existência neste caso seria há um jornalista, ou algo assim.
} 


\section{Conclusão}

Destas análises podemos observar, do ponto de vista da relação entre aposto e designação, que a relação apositiva, uma relação interna ao texto, que envolve modos diversos de integração das expressões linguísticas ao texto, envolve uma relação de atribuição de sentido aos nomes que leva a relações de DSDs como em

adeptos do canibalismo † índios tupinambás

Assim como

Jornalista $\dashv$ Alex Escobar.

Na mesma medida temos que considerar que

Viajante alemão $\dashv$ Staden.

Desta maneira, não só se sustenta a consideração de que os nomes próprios significam, como também se pode dizer que a construção da designação é produzida por relações de linguagem, do próprio modo de os termos se combinarem como pelo modo destes termos se integrarem diferentemente ao texto. A relação da linguagem e as coisas aparece assim como construída semanticamente pela enunciação.

Para finalizar esta reflexão, tomemos elementos de uma análise que apresentei em momentos anteriores (Guimarães, 1991), para sustentar melhor nosso objetivo geral: pensar a designação.

Consideremos em (3) a designação de cidadão:

(3)"Art. $6^{0}$. - São cidadãos brasileiros:

$1^{\circ}$. - Os que no Brasil tiverem nascido, quer sejam ingênuos ou libertos, ainda que o pai seja estrangeiro, uma vez que este não resida por serviço de sua nação".

O que aparece definido no texto é a categoria do cidadão brasileiro reescriturada por definição em (3), tal como mostra a paráfrase

(3') São cidadãos brasileiros os cidadãos (as pessoas) que no Brasil tiverem nascido, ingênuos ou libertos.

Um cidadão brasileiro é um cidadão que tiver nascido no Brasil. Isto significa que, semanticamente, o que se tem é que cidadão determina o sentido de brasileiro. Para ser brasileiro é necessário ser cidadão nascido no Brasil. Caberia, então, no caso, uma paráfrase do tipo

(3') Os nascidos no Brasil que não são cidadãos não são brasileiros.

Por outro lado temos em (3) uma relação de cidadãos com ingênuos e libertos. Observe-se que a expressão ingênuos ou libertos reescritura, por expansão explicativa, nascidos (pessoas ou cidadãos) no Brasil. Isto faz com que se tenha como elemento de paráfrase para esta expansão 
(3"') os cidadãos (pessoas) brasileiros são os cidadãos, ingênuos ou libertos, nascidos no Brasil.

Só são cidadãos os ingênuos ou libertos, os que são livres. Assim tem-se:

1.ingênuos (nascidos livres) e libertos (que não são mais escravos) determinam o sentido de (constitui a designação de) Cidadão, tal como mostram as paráfrases (3'), (3') e (3'',).

2.Cidadão determina o sentido de Brasileiro, tal como mostra a paráfrase (3').

3.Brasileiro (dadas estas atribuições de sentido) está em antonímia com escravo (o escravo é não liberto, não ingênuo).

Escravos designa os nascidos no Brasil que não são cidadãos, pois não são ingênuos nem libertos. Isto nos leva a um DSD como

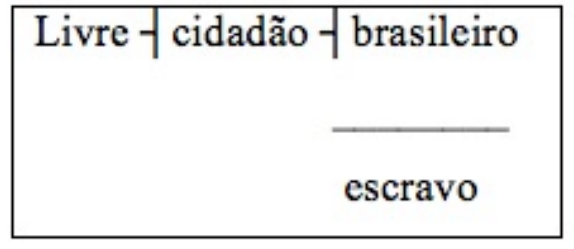

O que mostra que o conceito de cidadão, neste texto, significa a exclusão de parte da sociedade brasileira, nascidos no Brasil de então.

Quanto ao funcionamento semântico do aposto, precisamos levar em conta que na relação apositiva se sobrepõem dois aspectos: de um lado há a reescrituração apositiva que atribui o sentido de um termo sobre o outro, de outro lado, o modo de integração dos termos da relação apositiva ao texto apresenta uma importante diferença. Se tomamos aqui (2.1), temos, de um lado jornalista atribui sentido a Alex Escobar, de outro temos o que está dito por um outro enunciador, aludido pelo enunciador apresentado pelo alocutor, Alex Escobar é jornalista e, no caso de 2.3, Alex Escobar é jornalista da globo. Estamos diante de uma co-existência, de uma polissemia produzida pela sobreposição de uma reescrituração apositiva e a divisão politópica da cena enunciativa. E não se trata de dizer que a determinação explicaria a divisão ou o inverso. Isto porque as reescriturações que levam à consideração de que um elemento $a$ determina $b(\mathrm{a}-\mathrm{t} \mathrm{b})$ não recobre o que está afirmado na divisão dos lugares de enunciação. Ou seja, trata-se de uma sobreposição e não de um recobrimento. O que a própria relação apositiva coloca, de modo muito específico, é que para ser aquele que é referido por o jornalista, o viajante alemão, por exemplo, é preciso ser aquele que é significado pelo que jornalista designa. E isto significa no nome próprio pela história de enunciações do nome e em acontecimentos como estes analisados, nos quais o enunciador, que afirma algo, faz alusão ao que um outro enunciador significa, tal como no esquema apresentado mais acima.

Façamos uma síntese bem específica do percurso das sondagens realizadas:

1.Palavras e expressões designam de modo muito particular em virtude das relações linguísticas que apresentam pelos textos em que estão (pelos acontecimentos que as enuncia). A observação do aposto é particularmente interessante para sustentar esta posição.

Observando o funcionamento da relação apositiva pudemos ver que o nome próprio designa e pode ser o especificador de uma referência em virtude disso. 
2.A designação de cidadão, sobre a qual voltamos, tal como a encontramos no texto da primeira Constituição brasileira, não é uma referência a uma classe de objetos, é uma significação.

O mesmo se dá para Staden, e Alex Escobar, nomes próprios. Suas designações, e a análise do funcionamento apositivo é importante para se observar isso, não é a referência a um objeto único. A designação de cada um dos nomes é uma significação no texto em que está. Aí Staden significa algo como, por exemplo, viajante $\dashv$ Staden, Alex Escobar algo como jornalista † Alex Escobar.

3.Pela consideração da dinâmica da cena enunciativa, pudemos indicar as relações de dizeres internos a ela. Por exemplo, um enunciador alude o dito de outro enunciador; o alocutor (lugar social de dizer) apresenta o dito de um enunciador. Isso mostra que na medida em que as coisas já estão ditas fala-se permanentemente delas: é impossível não falar das coisas. A referência não é o fundamento do sentido, é algo que resulta, necessariamente, do sentido, da designação.

\section{REFERÊNCIAS}

GUIMARÃES, E. Produzindo o Sentido de um Nome de Cidade. Rua (UNICAMP), v. 20, p. 35-49, 2014.

GUIMARÃES, E. Aposto e Nome Próprio. Entremeios, v. 5, p. 1-8, 2012.

GUIMARÃES, E. Em Torno de um Nome Próprio de Cidade. Sobre a Produção dos Sentidos de uma Origem. Cadernos de Estudos Lingüísticos (UNICAMP), v. 53, p. 137-147, 2011.

Guimarães, E. Domínio Semântico de Determinação. A Palavra. Forma e Sentido. Campinas, Pontes/RG, 2007.

GUimarãeS, E. Semântica do Acontecimento. Campinas, Pontes, 2002.

GUIMARÃES, E. Os Sentidos de Cidadão no Império e na República no Brasil. Língua e Cidadania. Campinas, Pontes, 1996.

Recebido em: setembro de 2017.

Aprovado em: outubro de 2017.

\section{Como citar este trabalho:}

GUIMARÃES, E. Relações apositivas: dinâmica dos lugares de enunciação nas relações de designação. Traços de linguagem, v. 2, n. 1, p. 83-94, 2018. 